\title{
A systematic review of school meal nudge interventions to improve youth food behaviors
}

\author{
Jessica Jarick Metcalfe ${ }^{1}$, Brenna Ellison², Nader Hamdi ${ }^{1}$, Rachel Richardson² and Melissa Pflugh Prescott ${ }^{1 *}$ (D)
}

\begin{abstract}
Background: School meal programs have a large reach and thus are ideal environments in which to implement interventions targeting improved youth eating behaviors and reduced food waste. This systematic review summarizes the evidence on the effectiveness of school meal nudge interventions on influencing children's eating and waste behaviors.

Methods: Inclusion criteria required studies have participants in primary or secondary school (grades K-12) with interventions that occurred during school lunch or breakfast in the cafeteria and included at least one of the following outcomes: selection, consumption, waste, or school meal participation. Analyses of intervention outcomes were restricted to studies of strong and moderate quality.

Results: Twenty-nine studies were included in the quality assessment. Included interventions fell into three categories: 1) placement/convenience, 2) marketing/promotion, or 3) variety/portions. The 20 strong and moderate quality studies included in outcome analyses generally used strong data collection methods and study designs, but were limited by an overall lack of intervention fidelity checks. Multi-component interventions often did not use methods that allowed for separate analyses of outcomes for different intervention components.

Conclusions: School meal nudge interventions were positively associated with food selection, and had an inconsistent relationship with food consumption. There were few studies evaluating the impact of nudge interventions on meal participation or food waste. The limited evidence available links nudges to improved meal participation, as well as undesirable increases in food waste. Future research in this area should use methods that incorporate implementation metrics, attend to systems factors, and allow the outcomes of individual intervention components to be isolated.
\end{abstract}

Keywords: Behavioral economics, School meals, Food waste, Nudge

\section{Background}

About $95 \%$ of U.S. children do not meet the federal dietary recommendations for vegetable intake $[1,2]$. Concurrently, food waste is increasingly recognized as a major concern across the global supply chain [3, 4]. Wasted food is often linked to wasted resources, such as the land, water, and energy inputs to food production [4-6]. Food

\footnotetext{
* Correspondence: mpp22@illinois.edu

'Department of Food Science and Human Nutrition, University of Illinois at Urbana-Champaign, 905 South Goodwin Avenue, Urbana, IL 61801, USA Full list of author information is available at the end of the article
}

waste in school nutrition programs has received increasing attention since the mandate of the USA's Healthy, Hunger-Free Kids Act (HHFKA) [7], but evidence shows waste rates have not increased under HHFKA nutrition standards $[8,9]$. Even still, an average of $21-45 \%$ of each school meal is wasted [8-11] among the 30 million children participating in the U.S. National School Lunch Program [12], underscoring the missed opportunity for children to consume healthy food and mitigate waste.

Since food consumption and food waste are corollary behaviors, many schools have turned to the concept of 
"nudging" to improve students' eating (and wasting) behaviors in the school lunchroom environment. Thaler and Sunstein (2008) define a nudge as "any aspect of the choice architecture that alters people's behavior predictably without forbidding any options or significantly changing their economic incentives" [13] , [p. 6]. The concept of nudging is grounded in behavioral economics, which argues that consumers are susceptible to behavioral biases because they often make decisions based on mental shortcuts, or heuristics, which can subsequently lead to sub-optimal (in this case, less healthy or more wasteful) decisions [14-17]. In the case of food choices, for example, research has shown that consumers exhibit present-biased preferences, meaning they place more weight on immediate benefits (e.g., better taste, convenience) relative to delayed benefits (e.g., improved health) when making food decisions [14-16]. Also, consumers can be susceptible to visceral factors, such as sights or smells, when they are in a "hot" state such as being hungry or under stress $[15,16]$. Behavioral economists contend that nudging can be used to help consumers overcome these biases and ultimately improve food choice. In the context of the school lunchroom environment, nudges could include tactics like slicing fruit to make it more convenient for students to eat, re-naming fruit and vegetable dishes to make them more appealing, or identifying white milk as the 'featured' milk to encourage white milk as the default choice over chocolate milk.

Intervention strategies based in behavioral economics dominate school nutrition research and practice. In the U.S., nudges are a key component of the Smarter Lunchrooms Movement, which combines insights from behavioral economics, psychology, and marketing in an effort to reduce waste while improving student selection and consumption of vegetables and other healthy foods. Over 29,000 U.S. schools have implemented behavioral nudge interventions targeting school meals [18]. Yet, recent critiques have questioned whether their effects on consumer behavior are meaningful or overstated $[19,20]$. There are also significant gaps in knowledge related to the long-term impacts of nudges used in the school meal environment. Furthermore, school meal research generally does not take the influence of other important system factors, like the time available to eat [21], menu [22], or day of the week [23], into account when evaluating behavioral nudges. The complexity of school meal environments and the interrelated problems of food waste and dietary behavior require a systems approach that is missing from the available evidence on school meal nudges.

There have been two other literature reviews $[24,25]$ published on environmental approaches to improving the school nutrition environment, but both of them included interventions that are not nudges, such as changing nutrition policies [25], food pricing [24, 25], and/or providing incentives for healthy behavior [24]. Thus, there is no systematic assessment of the impact of behavioral nudges on school meal dietary behaviors. The aim of this study is to conduct a systematic review to determine the range and quality of available evidence of school meal nudges on student eating behaviors, such as school meal participation, food selection, consumption, and waste.

\section{Methods}

\section{Search strategy}

The systematic review protocol was based on the PRISMA (Preferred Reporting Items for Systematic Review and Meta-Analysis) guidelines [26]. The PICO-C (population, intervention, comparison, outcomes, context) framework was established a priori to determine the inclusion and exclusion criteria for the study. Population consisted of school children in grades Kindergarten - 12 (primary and secondary school students); Intervention had to focus on a classic nudge implemented in the cafeteria environment or marketing and promotion campaigns; eligible comparison groups included intervention versus post-intervention, control versus intervention, and exposed versus unexposed groups; Outcomes included sales, selection, consumption, waste, and school meal participation; Context required studies to be conducted during school lunch or breakfast in the cafeteria. Articles were retrieved from three databases (PubMed, Psych Info, and Web of Science) from June through August 2018 using search terms developed by the authors after a review of 35 known articles and review of the recommendations included on the Smarter Lunchrooms Scorecard [27]. The search terms were divided into two groups. The first included all possible combinations of 1) School lunch, school breakfast, school food, school nutrition, school cafeteria, or school canteen 2) Label*, nudg*, behavioral economics, choice architecture, marketing, environment", promot*, atmosphere, placement, chef, default option, or slic* and 3) Intake, choice, select", consum*, waste, sales, or participation. Group two was limited to 1) Smarter Lunchroom* and combined with 2) intake, choice, select", consum", waste, sales, or participation. Additionally, articles were excluded if they were 1) not in English and 2) were any format other than a published peer-reviewed paper. There were no exclusion criteria related to publication date. After duplicates were removed, two undergraduate research assistants reviewed the title and abstract to determine if PICO-C criteria were met; a faculty member resolved any disagreement between the research assistants. Articles were downloaded for full-text review if PICO-C criteria were satisfied. The references for each article that underwent full-text review were searched to identify additional papers. 


\section{Data extraction}

Targeted data extracted from the studies, using a standardized data extraction form, included: author(s), publication date, study setting, purpose and design, sample characteristics, intervention components and characteristics, data collection methods, intervention outcomes, assessment of intervention integrity, and study implications. For these studies, only data from intervention components that met PICO-C criteria were extracted. Each data extraction was performed initially by an author and verified for accuracy by a second author. A third author was consulted whenever unanimous agreements could not be reached by the first two authors. Studies that included both nudge intervention components and additional intervention components (such as classroom components) that did not meet PICO-C criteria were only included in the review if they used study designs that quantified the specific impact of a nudge in isolation. In these cases, only the data about the nudge intervention and control group were extracted.

\section{Data synthesis}

Meta-analysis could not be performed, as there was extensive heterogeneity among study designs, samples, intervention components, outcome measures and measurement techniques. A narrative synthesis was used to examine the interventions included in the review to describe themes and limitations present in the existing body of literature, and assess the overall quality of published nudge interventions. Study characteristics, intervention components, outcomes and effectiveness were summarized and tabulated to provide an overview of the studies included in the review. For discussion purposes, the nudge internventions for the included studies were reviewed and then classified into three categories of nudge interventions: 1) placement or convenience, 2) marketing or promotion, or 3) variety or portion sizes of foods. Studies that included two or more intervention components were considered "multi-component" interventions. Stata $15 \mathrm{MP}$ software was used to conduct all descriptive statistical analyses.

\section{Quality assessment}

Six criteria including study design, sampling, measurement techniques and methods, intervention integrity checks, confounders, and environmental/systems controls, from a modified version of the Effective Public Health Practice Project's Quality Assessment Tool for Quantitative Studies [28], were used to assess the quality of each study. Each criterion received a quality score of one, two, or three, and criterion quality scores were summed to yield global quality scores of strong, moderate, or weak for individual studies. Only studies that were of strong or moderate quality were included in final analyses. Quality score criteria and possible point ranges are listed in Table 1.

\section{Results \\ Study selection}

Figure 1 depicts the study search and selection process. The systematic database search yielded 2961 studies. After removing duplicate articles, and identifying 58 additional studies through reference search, 768 articles were excluded by title and abstract screening. Among the 63 articles assessed for eligibility, 34 were excluded for not being full-text original research articles, not meeting PICO-C guidelines, or for having been retracted since initial identification. Twenty-nine articles met the selection criteria and were included in the quality assessment.

\section{Study characteristics}

All studies included in the systematic review were conducted in developed countries, including the United States $(n=26)$, France $(n=1)$, Australia $(n=1)$, and the United Kingdom $(n=1)$. Sample sizes for included studies ranged from 25 students to approximately 19,000 students and from one to 21 schools $(n=4$ did not report sample sizes). Of the 29 studies, $20(69 \%)$ included elementary (primary) school students (grades K-5), 15 (52\%) included middle school students (grades 6-8), and 7 (24\%) included high school students (grades 9-12), with 13 studies (45\%) including participants across multiple age groups. Reported eligibility rates for the Free and Reduced Price Lunch Program (FRL) ranged from less than 10 to $100 \%$ ( $n=7$ did not report FRL eligibility rates). Study length ranged from 1 day to three academic years ( $n=2$ did not report study length). Table 2 summarizes included studies.

\section{Study quality}

The results of the quality assessment are displayed in Table 1. The global quality ratings of three studies $(10 \%)$ were of strong quality $[35,45,50)$, seventeen studies $(59 \%)$ were of moderate quality [23, 29-34, 36, 37, 41, 44, 46-48, 51, 55, 56], and nine studies (31\%) were of weak quality [38-40, 42, 43, 49, 52-54].

Twelve studies (41\%) used strong study designs, including nine cluster randomized trials [30,32, 36, 37, 41, 44, 45, 51, $55]$ and three crossover study designs [34, 46, 50]. Nine studies (31\%) used moderately strong study designs, including five non-randomized controlled trials [31, 33, 35, 47, 49] and four cross-sectional studies [23, 29, 43, 48]. Eight studies (28\%) used weak study designs, including six non-controlled trials $[38,42,52-54,56]$ and two before-after studies [39, 40]. All included studies $(n=29)$ used moderate quality sampling methods. None of the studies randomly selected schools, but three randomly selected individual participants within schools $[23,29,38]$, and the remaining twenty-five sampled all participants who were eligible for the study within the schools. 
Table 1 Study quality criteria and scores

\begin{tabular}{|c|c|c|c|c|}
\hline \multirow[t]{2}{*}{ Criterion of Study Quality } & \multicolumn{4}{|c|}{$\begin{array}{l}\text { Mean (SD) } \\
\text { Observed Range }\end{array}$} \\
\hline & $\begin{array}{l}\text { Weak } \\
\text { Studies } \\
(n=9)\end{array}$ & $\begin{array}{l}\text { Moderate } \\
\text { Studies } \\
(n=17)\end{array}$ & $\begin{array}{l}\text { Strong } \\
\text { Studies } \\
(n=3)\end{array}$ & $\begin{array}{l}\text { Full } \\
\text { Sample } \\
(n=29)\end{array}$ \\
\hline 1). Study Design: Was there a comparison group and were treatments randomized? & $\begin{array}{l}1.22 \\
(0.42) \\
1-2\end{array}$ & $\begin{array}{l}2.53(0.61) \\
1-3\end{array}$ & $\begin{array}{l}2.67 \\
(0.47) \\
2-3\end{array}$ & $\begin{array}{l}\mathbf{2 . 1 4} \\
(0.82) \\
1-3\end{array}$ \\
\hline $\begin{array}{l}\text { 2). Sampling Methods: Were schools and participants selected randomly or through convenience } \\
\text { sampling? }\end{array}$ & $\begin{array}{l}2.00(0) \\
2\end{array}$ & $\begin{array}{l}2.00(0) \\
2\end{array}$ & $\begin{array}{l}2.00(0) \\
2\end{array}$ & $\begin{array}{l}2.00(0) \\
2\end{array}$ \\
\hline $\begin{array}{l}\text { 3). Data Collection Methods/Measurement Techniques: Were valid and reliable methods used to } \\
\text { collect outcome data? }\end{array}$ & $\begin{array}{l}2.56 \\
(0.50) \\
2-3\end{array}$ & $\begin{array}{l}2.53(0.50) \\
2-3\end{array}$ & $\begin{array}{l}3.00(0) \\
3\end{array}$ & $\begin{array}{l}2.59 \\
(0.49) \\
2-3\end{array}$ \\
\hline $\begin{array}{l}\text { 4). Intervention Integrity Checks: Did the study include any announced or unannounced } \\
\text { intervention integrity checks? }\end{array}$ & $\begin{array}{l}1(0) \\
1\end{array}$ & $\begin{array}{l}1.35(0.48) \\
1-2\end{array}$ & $\begin{array}{l}2.33 \\
(0.94) \\
1-3\end{array}$ & $\begin{array}{l}1.34 \\
(0.60) \\
1-3\end{array}$ \\
\hline $\begin{array}{l}\text { 5). Demographic Confounders Controlled for: Were relevant demographic confounders (gender, } \\
\text { SES, race/ethnicity) controlled for in study design or analysis? }\end{array}$ & $\begin{array}{l}1(0) \\
1\end{array}$ & $\begin{array}{l}2.12(0.83) \\
1-3\end{array}$ & $\begin{array}{l}3.00(0) \\
3\end{array}$ & $\begin{array}{l}1.86 \\
(0.90) \\
1-3\end{array}$ \\
\hline $\begin{array}{l}\text { 6). Environmental/Systems Confounders: Were environmental/systems confounders controlled for } \\
\text { in study design or the analysis? }\end{array}$ & $\begin{array}{l}1.44 \\
(0.50) \\
1-2\end{array}$ & $\begin{array}{l}1.76(0.73) \\
1-3\end{array}$ & $\begin{array}{l}2.00 \\
(0.82) \\
1-3\end{array}$ & $\begin{array}{l}1.69 \\
(0.70) \\
1-3\end{array}$ \\
\hline $\begin{array}{l}\text { Total Study Quality Score } \\
\text { (sum of items 1-6) }\end{array}$ & $\begin{array}{l}9.22 \\
(0.63) \\
8-10\end{array}$ & $\begin{array}{l}12.29 \\
(1.02) \\
11-14\end{array}$ & $\begin{array}{l}15.00(0) \\
15\end{array}$ & $\begin{array}{l}11.62 \\
(1.99) \\
8-15\end{array}$ \\
\hline
\end{tabular}

Note. The total possible study quality score ranged from 6 to 18 . Scores for each study quality criterion were assigned based on whether the study exhibited strong (3), moderate (2), or weak (1) characteristics in each category. Studies with scores from 15 to 18 were categorized as strong $(n=3)$, scores from 11 to 14 were categorized as moderate $(n=17)$, and scores from 6 to 10 were categorized as weak $(n=9)$. Environmental/systems confounders included controlling for menu, time available to eat, and/or day of the week, and specifying if salad bar/self-service options were present

Data collection methods were generally strong $(n=17)$, and many studies $(n=15)$ measured multiple outcomes. Strong measurement methods consisted of valid and reliable data collection techniques for each outcome. The most common strong data collection techniques for each outcome category were as follows: participation - administrative data $(n=1)$, selection - sales data $(n=7)$, consumption - individual direct weighing ( $n=9)$, and waste - individual direct weighing $(n=2)$. Seventeen studies $(59 \%)$ used strong data collection methods [23, 29-32, 35, 38, 41, 42, 45-48, 50, 52-54] Zero studies used weak data collection methods. Intervention integrity checks were uncommon among included studies. Only two studies (7\%) used strong intervention integrity check methods [35, 45], which consisted of unannounced researcher observations. Six studies (21\%) used moderately strong intervention integrity check methods [23, 30, 32, 37, 44, 48], such as announced/planned researcher observations or selfreported intervention integrity checks. The remaining 21 studies $(74 \%)$ did not report using any intervention integrity or fidelity monitoring and were rated as weak in this category.

Ten studies (37\%) used strong methods to address potential confounders (gender, socioeconomic status, and race/ethnicity) and either had no important differences between groups at baseline or controlled for all important differences between groups or participants [29, 30, $32,33,35,36,45,47,50,51]$. Five studies $(17 \%)$ used moderately strong methods to address potential confounders and controlled for some (but not all) potential confounders at the individual level, or controlled for confounders at the school level [37, 44, 48, 55, 56]. Fourteen studies (48\%) used weak methods to address potential confounders and controlled for none of the potential confounders or did not provide information on demographics or differences between groups [23, 31, 34, 38$43,46,49,52-54]$. Few studies controlled for or reported on systems and environmental-level factors (specifying if salad bar/self-service options were present, and controlling for menu, time available to eat, and/or day of the week). Zero studies included pre-consumer waste assessments; this systems level factor was not included in the calculation of quality scores for this category. Four used strong methods to address systems factors [23, 29, $50,56]$, twelve studies used moderately strong methods [31, 33-35, 37-39, 41, 43, 46, 48, 54], and thirteen studies used weak methods to address systems factors $[30,32,36,40,42,44,45,47,49,51-53,55]$.

\section{Summary of intervention components and study outcomes}

The rest of the results section will exclusively discuss results from studies of strong and moderate quality. Eighteen studies measured selection, twelve studies measured 


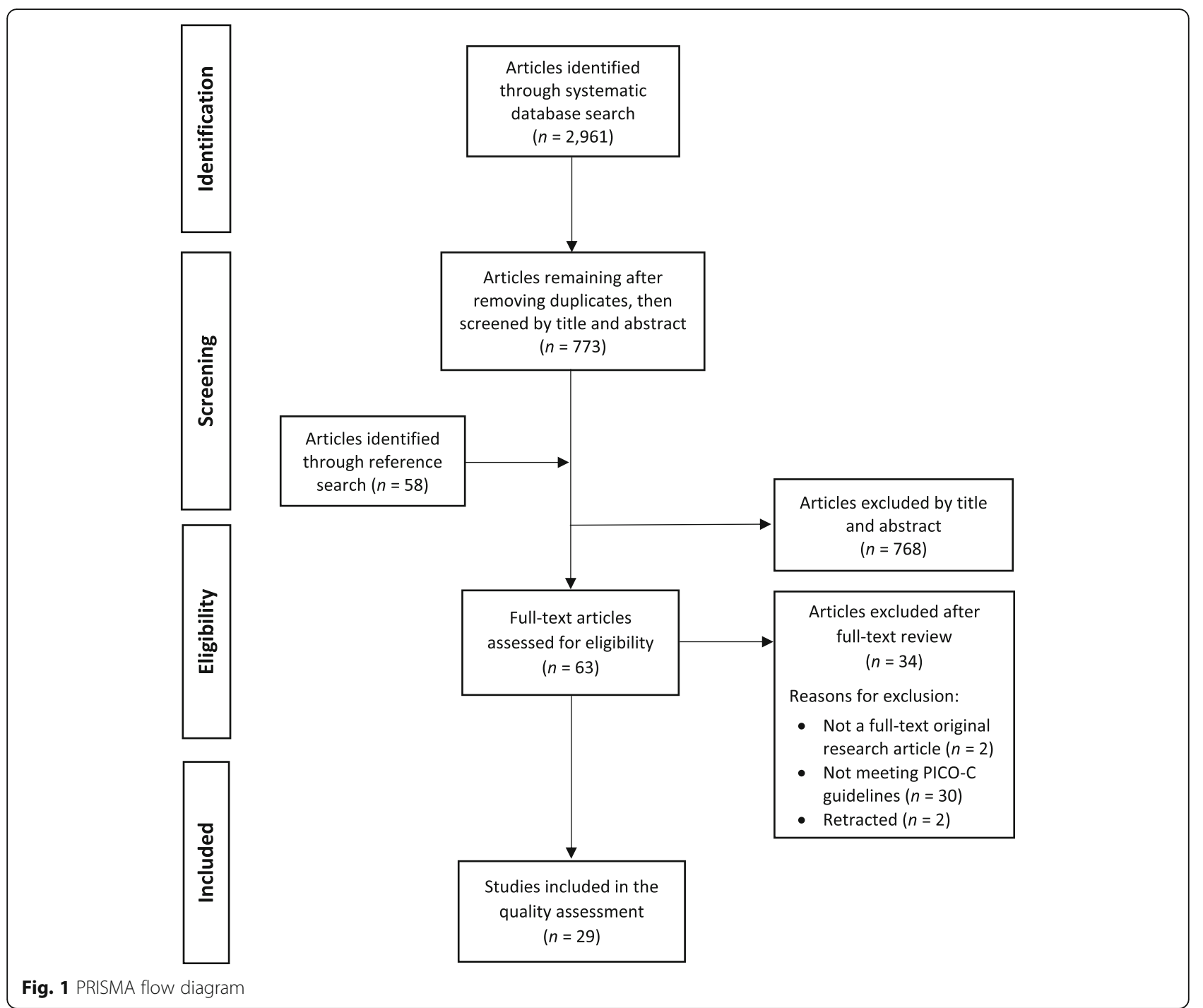

consumption, and four studies measured waste of school lunch foods. As shown in Fig. 2, fruits and vegetables were the predominant meal components examined across studies. One study [45] measured student participation in school breakfast. Studies are grouped for discussion based on intervention type (placement or convenience; marketing or promotion; variety or portion sizes of foods). Studies that included two or more intervention components were considered to be multi-component studies and are discussed separately. Studies with multiple components that fall in the same category [36, 41] will be included in both multicomponent and specific intervention type sections.

\section{Multi-component studies}

The most common intervention component used in multicomponent interventions ( $n=9,45 \%$ of included studies) was changing the placement of food or milk [30, 35-37]. Multi-component intervention study designs included six cluster randomized trials [30,32, 36, 37, 41, 44], one crossover study [34], and two non-randomized controlled trials $[35,47]$. Outcomes of multi-component studies were largely positive (73\%), but there were also more null outcomes (23\%) than in most other intervention categories (see Supplemental Figure 1). However, only two of the multicomponent studies (23\%) used study designs or statistical methods that allowed authors to separate effects for each intervention component $[36,41]$. The large proportion $(77 \%)$ of multi-component studies whose effects cannot be analyzed separately by intervention component limits our ability to draw strong conclusions about the impact of individual intervention components. The rest of this section will only provide detailed results for strong studies and multi-component studies with designs that allow for isolating effects.

Two $(22 \%)$ of the nine multi-component studies used different experimental conditions to isolate the effects of each intervention component $[36,41]$. Both studies were of moderate quality. Goto and colleagues (2013) [36] implemented an intervention that modified the availability 
Table 2 Summary of school meal nudge studies $(n=29)$ characteristics and outcomes

\begin{tabular}{|c|c|c|}
\hline $\begin{array}{l}\text { Authors, Date [Reference } \\
\text { Number] } \\
\text { Study Design } \\
\text { Study Length } \\
\text { Sample Details }\end{array}$ & $\begin{array}{l}\text { Intervention Component(s) } \\
\text { (Component Duration) }\end{array}$ & $\begin{array}{l}\text { Outcome Categories: } \\
\text { Measurement } \\
\text { Technique } \\
\text { (Number of Data } \\
\text { Collection Days) }\end{array}$ \\
\hline
\end{tabular}

Adams et al., 2005 [23] Cross-Sectional Study Study Length: 1 day Location: California Age Group: Grades 1-5 $n=\mathrm{NR}$, 4 schools Quality Rating: Moderate

Adams et al., 2016 [29] Cross-Sectional Study Study Length: 1 day Location: Arizona Age Group: Middle School $n=533$ students, 6 schools Quality Rating: Moderate
- Compared schools with existing salad bars to schools without salad bars (Duration NR)

(n)

- Changing placement of salad bar to inside serving line, instead of outside the serving line (Duration NR)
Selection:
Direct Weighing
Individual
(1 day)
Consumption:
Direct Weighing
Individual
(1 day)
Selection:
Direct Weighing
Individual
(6 days)
Consumption:
Direct Weighing
Individual
(6 days)
Waste:
Individual
Direct Weighing
(6 days)
$\oslash$ No significant difference in selection of fruits and vegetables at schools with and without salad bars (NS)
$\oslash$ No significant difference in consumption of fruits and vegetables at schools with and without salad bars (NS)
$\uparrow$ Students self-served 5.38 times (95\% Cl: 4.04-7.17) more fresh fruits and vegetables by weight when the salad bar was inside the lunch line (141.2 g) compared to outside ( $26.6 \mathrm{~g}$ )
$\uparrow$ Students were 4.82 times (95\% Cl: 3.40-6.81) more likely to consume more fresh fruits and vegetables when the salad bar was inside the lunch line $(74.1 \mathrm{~g})$ compared to outside (16.6 g)
$\uparrow$ Students wasted more fruits and vegetables when the salad bar was inside the lunch line $(43 \%, 29.9 \mathrm{~g})$ compared to outside $(12 \%, 11.7 \mathrm{~g})$ $(p=N R)$

Cohen et al., 2015 [30]

Cluster Randomized Trial Study Length: 10 months Location: Massachusetts Age Group: Grades 1-8 $n=1587$ students, 10 schools

Quality Rating: Moderate
- Using attractive bowls or baskets vegetables

- Changing fruit and vegetable placement

(All components 4 months)
- Signage and images promoting fruits and

$\uparrow$ Fruit selection was greater at intervention schools (54.3\%) than control schools (51.1\%) (OR: 1.45, 95\% Cl: 1.13-1.87)

$\uparrow$ Vegetable selection was greater at intervention schools (33.7\%) than control schools (50.6\%) (OR: 1.91, 95\% Cl: 1.46-2.50)
Selection:

Visual Observation (6 days)

Consumption: Direct Weighing Individual (6 days) $\oslash$ No significant difference in milk selection between intervention and control schools (NS)

$\oslash$ No significant difference in fruit consumption between intervention and control schools (NS)

$\oslash$ No significant difference in vegetable consumption between intervention and control schools (NS) $\oslash$ No significant difference in milk consumption between intervention and control schools (NS)

$\uparrow$ Decrease in the number of servings selected for pepperoni pizza, cheeseburgers, bacon cheeseburgers, and chicken dishes with $>20 \mathrm{~g}$ of fat per serving $(p<.05)$

$\uparrow$ Increase in the number of servings selected for cheese pizza, hamburgers, and veggie burgers $(p<.05)$

Selection:

Sales Data

(4 months) (non-student developed)

- Online pre-orders

- Stop Light Labeling

- Positive prompting and reinforcement for healthy choices $\downarrow$ Fewer calories in selected lunches among intervention (1104 kJ) compared to control (1565 kJ) participants at post-intervention $(p<.001)$ lunches among intervention (2.87 g) $\downarrow$ Less saturated fat in selected 
Table 2 Summary of school meal nudge studies $(n=29)$ characteristics and outcomes (Continued)

\begin{tabular}{|c|c|c|}
\hline $\begin{array}{l}\text { Authors, Date [Reference } \\
\text { Number] } \\
\text { Study Design } \\
\text { Study Length } \\
\text { Sample Details }\end{array}$ & $\begin{array}{l}\text { Intervention Component(s) } \\
\text { (Component Duration) }\end{array}$ & $\begin{array}{l}\text { Outcome Categories: } \\
\text { Measurement } \\
\text { Technique } \\
\text { (Number of Data } \\
\text { Collection Days) }\end{array}$ \\
\hline
\end{tabular}

Quality Rating: Moderate (All components 2 months)

compared to control $(4.84 \mathrm{~g})$ participants at post-intervention $(p<.001)$

$\downarrow$ Less sodium in selected lunches among intervention (400 mg) compared to control (527 mg) participants at post-intervention $(p<.001)$

$\oslash$ No significant difference in sugar content of selected lunches between intervention and control at postintervention (NS)
Elbel et al., 2015 [33] - Introduction of water jet

Non-Randomized Controlled (Approximately 10 months)

Trial

Study Length: 10 months

Location: New York

Age Group: Grades K - 12

$n=19,000$ students, 19

schools

Quality Rating: Moderate

Elsbernd et al., 2016 [34]

Crossover Study Design

Study Length: 12 weeks

Location: Minnesota

Age Group: Grades K - 5

$n=800$ students, 4 schools

Quality Rating: Moderate
- Verbal prompts for healthy item selection and/or consumption

- Serving vegetables first in isolation

(All components 3 days)
Selection:

Visual Observation

(4 days)

election:

Sales Data

(5 days)

Consumption:

Visual Observation

(5 days)

Waste:

Visual Observation

(5 days)

Selection:

Sales Data

(378 days)
Trial

Study Length: 2 academic

years

Location: United Kingdom

Age Group: Middle \& High

School

$n=2200$ students, 2 schools

Quality Rating: Strong

Goto et al., 2013 [36]

Cluster Randomized Trial

Study Length: 1 month

(approx.)

Location: California

Age Group: Grades 1-6

$n=677$ students, 3 schools

Quality Rating: Moderate
- Changing food placement posable pots/trays used to serve meals, prefilled pots/trays)

- Promotional material (smiley stickers on packaging and posters, end of shelf label, encouraging posters) (All components 6 weeks)

- Treatment 1: Increased white milk quantity available in the milk cooler compared to chocolate milk

- Treatment 2: Students must request chocolate milk (Both conditions 1 week) $\uparrow$ Three months after implementation, there was a larger increase in water selection among intervention (+ 23\%) schools compared to control schools $(+2 \%)(p<.001)$

$\uparrow$ Ten months after implementation, there was a larger increase in water selection among intervention (+22\%) schools compared to control schools $(-2 \%)(p<.001)$

$\uparrow$ Selection of peppers was greater on the intervention days (65\%) when vegetables were served first in isolation compared to control days

$\uparrow$ Consumption of peppers was greater on the intervention days (4.1 g) when vegetables were served first in isolation compared to control days (mean 1.4 g) $(p<.0001)$

$\uparrow$ Waste of peppers was greater on the intervention days (53-64\%) when vegetables were served first in isolation compared to control days $(8-38 \%)(p=N R)$

$\uparrow$ Students were 2.5 times more likely (OR: 2.49, 95\% Cl: 2.03-3.06) to select the designated items (whole fruit, fruit sandwiches containing salad) during the intervention period than at baseline $(p<.001)$

$\uparrow$ Students were 3 times as likely to choose a fruit, vegetable, or salad item during the intervention relative to baseline (OR: 3.04, 95\% Cl: 2.50 3.69) $(p<.001)$

Selection:

Visual Observation (10 days)

$\uparrow$ At treatment 1 school (increased milk quantity), selection of white milk increased by $18 \%$ between pre- $30 \%$, 74 students) to post-intervention (48\%, 118 students) $(p<.001)$

$\oslash$ No significant change in selection of white milk in treatment 2 school (ask for chocolate) (NS) $\oslash$ No significant change in white milk consumption at either treatment $(8 \%)(p<.0001)$ salad, vegetarian specials, and 
Table 2 Summary of school meal nudge studies $(n=29)$ characteristics and outcomes (Continued)

\begin{tabular}{|c|c|c|c|}
\hline $\begin{array}{l}\text { Authors, Date [Reference } \\
\text { Number] } \\
\text { Study Design } \\
\text { Study Length } \\
\text { Sample Details }\end{array}$ & $\begin{array}{l}\text { Intervention Component(s) } \\
\text { (Component Duration) }\end{array}$ & $\begin{array}{l}\text { Outcome Categories: } \\
\text { Measurement } \\
\text { Technique } \\
\text { (Number of Data } \\
\text { Collection Days) }\end{array}$ & Outcome Results \\
\hline
\end{tabular}

Quality Rating

Individual school (NS)
(30 days)

Greene et al., 2017 [37]

Cluster Randomized Trial

Study Length: 9 weeks

Location: New York

Age Group: Grades 5-8

$n=2108$ students, 10

schools

Quality Rating: Moderate
- Fruit placed first on lunch line

- Served two fruit options instead of one

- Slicing fruit

- Using attractive bowls for whole fruits

- Creative, descriptive names to market fruit items (non-student developed)

- Fruit "factoids" (promotions)

(All components 6 weeks)
Hakim et al., 2013 [38]

Non-Controlled Trial

Study Length: 2 weeks (approx.)

Location: Kansas

Age Group: Grades K - 8

$n=2064$ students, 1 schoo

Quality Rating: Weak

Hanks et al., 2012 [39]

Before-After Study

Study Length: 3 months

Location: New York

Age Group: High School

$n=362$ students, 1 school

Quality Rating: Weak
- Increasing the number of fruit and vegetable choices and variety offered each day (1 month)

- Created a convenience line in which only options considered healthy (sub sandwich bar, salad bar, vegetables, whole fruit, fruit parfait, flavored milks) were offered

(2 months)
Consumption: Direct Weighing Individual (20 days)

Selection: Self-Reported Survey with no validity or reliability information provided (4 days)

Consumption:

Direct Weighing Individual

(4 days)

- Using attractive bowls or baskets

- Changing food placement

- Creative, descriptive names to market food items (non-student developed)

- Verbal prompts to promote healthy items - Creating healthy convenience line with only submarine sandwiches, fruit and vegetable sides (All components 2 months)

- Treatment 1: Branded vegetable characters featured on vinyl promotional banners
Consumption: Visual Observation (Average of 5 baseline and 4 intervention days per school) $\uparrow$ Increase in average fruit selection from pre- (.59 servings) to postintervention (.80 servings) $(p<.001)$ $\uparrow$ Increase in average vegetable selection from pre- (.67 servings) to post-intervention (.98 servings) $(p<.001)$

$\uparrow$ Increase in average white milk selection from pre- (.10 servings) to post-intervention (.14 servings) $(p<.001)$

$\uparrow$ Increase in average fruit consumption from pre- (.73 servings) to post-intervention (.83 servings) $(p<.001)$

$\uparrow$ Increase in average vegetable consumption from pre- (.57 servings) to post-intervention (.86 servings) $(p<.001)$

$\oslash$ No change in average white milk consumption from pre- to postintervention (NS)

$\uparrow$ Fruit consumption increased between pre-intervention (40\%) and post-intervention (67\%) $(p<.01)$ $\uparrow$ Vegetable consumption increased between pre-intervention (23\%) and post-intervention $(41 \%)(p<.01)$

$\uparrow$ Increase in selection of healthy foods (salad bar, vegetables, fruit, fruit parfaits, and sub sandwiches) from pre- (mean .66 items) to postintervention (mean .79 items) $(p<.001)$

$\uparrow$ Selection of flavored milk increased from pre- (mean 0.74 items) to postintervention (mean 0.85 items) $(p<.001)$

$\oslash$ No significant change in plain milk selection (NS)

$\downarrow$ Consumption of less healthy foods decreased by $27.9 \%(p<.001)$

$\uparrow$ Students selecting fruits increased from pre- $(47.3 \%)$ to post-intervention

$\uparrow$ Students selecting vegetables increased from pre- $(35.8 \%)$ to post- $\uparrow$ Increase in average daily vegetable and salad servings selected from pre$(53.7 \%)(p=.012)$

intervention $(44.0 \%)(p<.001)$

Sales Data

(12 days)
Hanks et al., 2016 [41] Cluster Randomized Trial 
Table 2 Summary of school meal nudge studies $(n=29)$ characteristics and outcomes (Continued)

\begin{tabular}{|c|c|c|}
\hline $\begin{array}{l}\text { Authors, Date [Reference } \\
\text { Number] } \\
\text { Study Design } \\
\text { Study Length } \\
\text { Sample Details }\end{array}$ & $\begin{array}{l}\text { Intervention Component(s) } \\
\text { (Component Duration) }\end{array}$ & $\begin{array}{l}\text { Outcome Categories: } \\
\text { Measurement } \\
\text { Technique } \\
\text { (Number of Data } \\
\text { Collection Days) }\end{array}$ \\
\hline
\end{tabular}

Quality Rating

Study Length: 6 weeks Location: New York Age Group: Elementary School

$n=1133$ students, 10

schools

Quality Rating: Moderate

Hunsberger et al. 2014

[42]

Non-Controlled Trial

Study Length: 2 months

Location: Oregon

Age Group: Grades 6-8

$n=531$ students, 1 school

Quality Rating: Weak

Johnson et al., 2017 [43]

Cross-Sectional Study

Study Length: NR

Location: Louisiana

Age Group: Grades 7-12

$n=718$ students, 21 schools

Quality Rating: Weak

\begin{abstract}
Kenney et al., 2015 [44]
Cluster Randomized Trial

Study Length: 2 months

Location: Massachusetts

Age Group: Elementary,

Middle, and High School

$n=$ NR, 10 schools

Quality Rating: Moderate
\end{abstract}

Larson et al., 2018 [45]

Cluster Randomized Trial

Study Length: 3 academic

years

Location: Minnesota

Age Group: Grades 9-12

$n=364$ students, 8 schools

Quality Rating: Strong

Miller et al., 2015 [46]

Crossover Study Design Study Length: 4 months (approx.)

Location: Minnesota

Age Group: Grades K - 5

$n=758$ students, 1 school

Quality Rating: Moderate
- Treatment 2: Television promotional segments

- Treatment 3: Branded vegetable characters

featured on vinyl promotional banners and television

promotional segments

(All conditions 4 weeks)

- Calorie labels at point of purchase

(1 month) schools without salad bars

(Duration NR)

- Promotional signage highlighting water source locations and promoting consumption (16-23 days)

- Cup dispensers located next to cafeteria water fountains

(5-22 days)

- Implementing a grab-and-go breakfast cart before school

(1 year intervention)

- Provided increased portions sizes for orange

wedges, baby carrots, greens beans, and applesauce as the default portion size

(Duration NR)

(6 weeks)

(60 servings) to post-intervention (185 servings) in treatment 3 schools $(p=.028)$

$\oslash$ No significant changes from pre- to post-intervention in vegetable and salad servings selected in treatment 1 and treatment 2 schools (NS)

Consumption:

Direct Weighing

Aggregate

(Number of days NR)

$\downarrow$ Decrease in calories consumed between pre- $(668 \mathrm{Kcal})$ and postintervention (621 Kcal) $(p=.0040)$ $\downarrow$ Decrease in fat consumed between pre- $(23.1 \mathrm{~g})$ and post-intervention $(21.1 \mathrm{~g})(p=.0025)$

Consumption:

Self-Administered 24-

Hour Dietary Recall with no validity or reliability information provided

(Number of days NR)

Selection:

Visual Observation

(95 days)

Consumption:

Visual Observation (95 days)

Participation: Administrative Data ( 2 years baseline and 1 year intervention data) $\uparrow$ Students in salad bar schools had significantly higher median energy consumption during lunch (452 kcal) than students in non-salad bar schools (395 kcal) ( $p=.0136)$ $\downarrow$ Less fruit was consumed in salad bar schools (.06 cups) than non-salad bar schools (0.25 cups) ( $p=.0061$ ) $\oslash$ No significant differences in vegetable consumption (NS)

$\uparrow$ Larger increase from pre- to postintervention in students who take free water during lunch period among intervention $(+7.3 \%)$ compared to control $(-2.0 \%)(p<.001)$

$\uparrow$ Larger increase from pre- to postintervention in water consumption among intervention (+ $0.53 \mathrm{oz}) \mathrm{com}$ pared to control $(-0.06 \mathrm{oz})(p<.001)$

$\uparrow$ Participation in school breakfast program increased from $13.0 \%$ in the first baseline year (T1) to $22.6 \%$ in the intervention year (T3) $(p=0.03)$
Selection:

Direct Weighing Individual

(3 days)

Consumption:

Direct Weighing

Individual

(3 days) $\uparrow$ Selection of oranges was higher on intervention days (51\%) compared to control days $(35 \%)(p<.0001)$

$\downarrow$ Selection of applesauce was lower on intervention days (36\%) compared to control days (46\%) $(p<.0001)$ $\oslash$ No significant difference in green bean selection (NS)

$\uparrow$ Consumption of applesauce was greater on intervention days $(119 \mathrm{~g})$ compared to control (77 g) $(p<.001)$ $\uparrow$ Consumption of orange slices was greater on intervention days (37 g) compared to control (22 g) $(p<.001)$ $\uparrow$ Consumption of carrots was greater on intervention days (33 g) compared to control (20 g) $(p=.02)$ 
Table 2 Summary of school meal nudge studies $(n=29)$ characteristics and outcomes (Continued)

\begin{tabular}{|c|c|c|}
\hline $\begin{array}{l}\text { Authors, Date [Reference } \\
\text { Number] } \\
\text { Study Design } \\
\text { Study Length } \\
\text { Sample Details }\end{array}$ & $\begin{array}{l}\text { Intervention Component(s) } \\
\text { (Component Duration) }\end{array}$ & $\begin{array}{l}\text { Outcome Categories: } \\
\text { Measurement } \\
\text { Technique } \\
\text { (Number of Data } \\
\text { Collection Days) }\end{array}$ \\
\hline
\end{tabular}

$\oslash$ No significant difference in green bean consumption
Waste:

Direct Weighing Individual

(3 days)

Miller et al., 2016 [47] - Treatment 1: Pre-orders

Non-Randomized Controlled - Treatment 2: Pre-orders with behavioral nudge

Trial

Study Length: 4 weeks

Location: Florida

$n=169$ students, 1

combined elementary and

middle school

Quality Rating: Moderate (message alert if the student did not select a complete meal)

(All conditions 2 weeks)

Selection:

Video Recorded

Observation

(6 weeks)
Age Group: Grades 4-7

$\uparrow$ Waste of fruits and vegetables was $11-125 \%$ greater on intervention days compared to control days ( $p=N R$ )

$\uparrow$ Increases in selection of vegetables from pre- to post-intervention were significant for treatment 1 (pre-orders only, $+17.6 \%, p<.001)$ and treatment 2 (pre-order with behavioral nudge, + $24.6 \%, p<.001)$, but not control (+ $5.4 \%, p=\mathrm{NS}$ )

$\uparrow$ Increases in selection of fruits from pre- to post-intervention were significant for treatment 1 (pre-orders only, $+23.0 \%, p<.001)$ and treatment 2 schools (pre-order with behavioral nudge, $+37.8 \%, p<.001)$ but not control $(+4.8 \%, p=\mathrm{NS})$

$\uparrow$ Increases in selection of low-fat milk from pre- to post-intervention were significant for treatment $1(+7.3 \%$, $p=.011)$, treatment $2(+12.2 \%$ $p<.001)$, and control (+ 20.7\%, $p=.011)$

Moreno-Black et al., 2017 [48]

- Fruit and vegetable placement on salad bar vs hot line

Repeated Cross-Sectional

(Spring and Fall semester)

Selection:

Digital Photography

(Number of days NR)

(Longitudinal)

Study Length: 10 months

(approx.)

Location: Oregon

Age Group: Grades 1-5

$n=3000$ students, 7 schools

Quality Rating: Moderate

Morizet et al., 2012 [49] Non-Randomized Controlled Trial

Study Length: 2 days

Location: France

Age Group: Elementary and

Middle School

$n=227$ students, 3 schools

Quality Rating: Weak

Redden et al., 2015 [50]

Crossover Study Design

Study Length: 3 months

Location: USA

Age Group: Grades K - 5

$n=755$ students, 1 school

Quality Rating: Strong
- Treatment 1: Basic descriptive label (i.e., new carrot recipe)

- Treatment 2: Model-related label (i.e new carrot recipe, Special Mix for Super Heroes)

- Control Group: No labels

(All conditions 2 days)

- Offering youth vegetables in a small cup prior to moving through the lunch line, instead of only serving vegetables through the lunch line (Field Study: 1 control day, 1 intervention day, 3 months apart)

(Longitudinal: 1 control/baseline day, 3 intervention days, 1 control day, over 3 month period)
Selection: Visual Observation (6 days)

Selection: Visual Observation (Field Study: 2 days, Longitudinal: 5 days) $\uparrow$ Students were more likely to select fruit if when it was placed on the hot lunch line $(p<.05)$

$\uparrow$ Students were more likely to select any vegetable when fruit was placed on the hot lunch line $(p<.001)$ $\uparrow$ Students were more likely to select at least one healthy vegetable item when both fruit $(p<.001)$ and vegetables $(p<.05)$ were placed on the hot lunch line

$\uparrow$ Selection of new vegetable dish was greater for treatment $1(p=.012)$ and treatment 2 ( $p=.002$ ) compared to control

$\oslash$ No significant difference between treatment 1 and treatment 2 in selection of familiar and new dishes (NS)

$\oslash$ Field Study: Likelihood of selecting carrots from lunch line did not differ between treatment and control days (NS)

$\downarrow$ Longitudinal: Percentage of line was higher on the baseline control day (13.8\%) than the first treatment day $(4.1 \%, p<.0001)$, the second $(9.4 \%, p<.01)$, and the third treatment day $(5.3 \%, p<.0001)$ $\downarrow$ Longitudinal: Percentage of students selecting broccoli from lunch students selecting broccoli from lunch 
Table 2 Summary of school meal nudge studies $(n=29)$ characteristics and outcomes (Continued)

\begin{tabular}{|c|c|c|c|}
\hline $\begin{array}{l}\text { Authors, Date [Reference } \\
\text { Number] } \\
\text { Study Design } \\
\text { Study Length } \\
\text { Sample Details }\end{array}$ & $\begin{array}{l}\text { Intervention Component(s) } \\
\text { (Component Duration) }\end{array}$ & $\begin{array}{l}\text { Outcome Categories: } \\
\text { Measurement } \\
\text { Technique } \\
\text { (Number of Data } \\
\text { Collection Days) }\end{array}$ & Outcome Results \\
\hline
\end{tabular}
treatment day $(9.4 \%, \mathrm{NS})$

\author{
Schwartz et al., 2007 [51] \\ Cluster Randomized Trial \\ Study Length: 2 months \\ (approx.) \\ Location: Connecticut \\ Age Group: Grades 1-4 \\ $n=323$ students, 2 schools \\ Quality Rating: Moderate
}

Siegel et al., 2015 [52]

Non-Controlled Trial

Study Length: 4 months

Location: Ohio

Age Group: Grades K - 6

$n=297$ students,

1 school

Quality Rating: Weak

Swanson et al., 2009 [53]

Non-Controlled Trial

Study Length: NR

Location: Kentucky

Age Group: Grades K - 4

$n=491$ students,

1 school
- Verbal prompts promoting healthy items

- Smiley face signs placed next to encouraged items (7 weeks)

- Intermittent verbal reminders

(Intermittently over 7 weeks)
- Slicing apples and oranges before serving

(1 day intervention condition, 1 day control condition)
Quality Rating: Weak (Duration NR)

Direct Weighing

- Changing fruit and vegetable placement

- Creative, descriptive names to market food items (non-student developed)

- Menu displays with serving size suggestions

Location: Minnesota

Age Group: Grades 1-4

(All components 4 months)

Quality Rating: Weak

Wansink et al., 2013 [55]

Cluster Randomized Trial
- Slicing apples
(Duration NR)
Consumption:

Direct Weighing

Individual

(Field Study: 2 days,

Longitudinal: 5 days)

Selection:

Visual Observation

(2 days)

Consumption:

Visual Observation

(2 days)

Selection:

Sales Data

(Number of days NR)

Selection:

Digital Photography

(2 days)

Consumption:

Digital Photography (2 days)

Selection:

Individual

(4 days)

$\uparrow$ Field Study: Students consumed $10.3 \mathrm{~g}$ more carrots total on treatment day $(12.7 \mathrm{~g})$ than control day $(2.4 \mathrm{~g})$ $(p<.0001)$

$\uparrow$ Longitudinal: Students consumed more broccoli on the first treatment day $(3.99 \mathrm{~g})$, second treatment day $(4.06 \mathrm{~g})$ and the third treatment day $(2.10 \mathrm{~g})$ than both baseline control $(0.84 \mathrm{~g})$ and final control $(0.90 \mathrm{~g})$ days $(p<.0001$ for all treatment-control comparisons)

$\uparrow$ Students were more likely (OR: 1.9 $95 \% \mathrm{Cl}: 1.1-3.3)$ to select a serving of fruit in the intervention school (48\%) compared to the control school (32\%)

$\uparrow$ Students who selected fruit were more likely (OR: $2.3,95 \% \mathrm{Cl}$ : 1.3-4.2) to consume fruit in the intervention school (87\%) compared to the control school (65\%)

$\uparrow$ Increased plain white fat free milk selection from 7.4 to $17.9 \%$ of students $(p<.001)$

$\downarrow$ Decrease in low-fat chocolate milk selection from 86.5 to $77.1 \%$ of students $(p<.001)$

$\oslash$ No significant change in overall milk purchases (NS)

$\oslash$ No significant change in fruit purchases (NS)

$\uparrow$ Selection of sliced oranges (16.2, 95\% Cl: 13.0-19.7) was greater than selection of whole oranges $(5.5,95 \%$ Cl: 3.6-7.9)

$\oslash$ No significant difference in apple selection (NS)

$\uparrow$ More students consumed entire serving of sliced oranges $(10.2,95 \% \mathrm{Cl}$ : 7.6-13.3) than whole oranges (2.3, $95 \%$ Cl: 1.1-4.0)

$\oslash$ No significant difference in apple consumption (NS)

$\uparrow$ Percent of students selecting a serving of fruit increased from 95.5 to $98.1 \%(p=.02)$

$\oslash$ No significant change in vegetable selection (NS)

Consumption:

Direct Weighing Individual

(4 days)

Selection: Visual Observation $\oslash$ No significant change in fruit consumption (NS)

$\oslash$ No significant change in vegetable consumption (NS)

$\uparrow$ Intervention schools with fruit slicers had a larger increase in average daily 
Table 2 Summary of school meal nudge studies $(n=29)$ characteristics and outcomes (Continued)

\begin{tabular}{|c|c|c|c|}
\hline $\begin{array}{l}\text { Authors, Date [Reference } \\
\text { Number] } \\
\text { Study Design } \\
\text { Study Length } \\
\text { Sample Details } \\
\text { Quality Rating }\end{array}$ & $\begin{array}{l}\text { Intervention Component(s) } \\
\text { (Component Duration) }\end{array}$ & $\begin{array}{l}\text { Outcome Categories: } \\
\text { Measurement } \\
\text { Technique } \\
\text { (Number of Data } \\
\text { Collection Days) }\end{array}$ & Outcome Results \\
\hline \multirow{3}{*}{$\begin{array}{l}\text { Study Length: } \\
2 \text { weeks (approx.) } \\
\text { Location: New York } \\
\text { Age Group: Middle School } \\
n=643 \text { students, } \\
6 \text { schools } \\
\text { Quality Rating: Moderate }\end{array}$} & & (4 days) & $\begin{array}{l}\text { apple sales }(10 \%) \text { compared to control } \\
\text { schools }(6 \%)(p<.01)\end{array}$ \\
\hline & & $\begin{array}{l}\text { Consumption: } \\
\text { Visual Observation } \\
\text { ( } 4 \text { days) }\end{array}$ & $\begin{array}{l}\oslash \text { No significant changes in total } \\
\text { apple consumption from pre- to post- } \\
\text { intervention at treatment schools (NS) }\end{array}$ \\
\hline & & $\begin{array}{l}\text { Waste: } \\
\text { Visual Observation } \\
\text { (4 days) }\end{array}$ & $\begin{array}{l}\oslash \text { No significant difference in total } \\
\text { apple waste (by weight) from pre- to } \\
\text { post-intervention at treatment schools } \\
\text { (NS) }\end{array}$ \\
\hline $\begin{array}{l}\text { Zellner et al., } 2016 \text { [56] } \\
\text { Non-Controlled Trial } \\
\text { Study Length: } \\
2 \text { months } \\
\text { Location: Pennsylvania } \\
\text { Age Group: Grades 3-4 } \\
n=25 \text { students, } \\
1 \text { school } \\
\text { Quality Rating: Moderate }\end{array}$ & $\begin{array}{l}\text { - Offering fruit at the end of the meal, } \\
\text { instead of during the meal } \\
\text { (1 day intervention condition, } 1 \text { day control condition) }\end{array}$ & $\begin{array}{l}\text { Consumption: } \\
\text { Visual Observation } \\
\text { ( } 2 \text { days) }\end{array}$ & $\begin{array}{l}\uparrow \text { Larger percent of students ate at } \\
\text { least some of the vegetable (kale } \\
\text { salad) in intervention ( } 100 \%) \\
\text { compared to control }(40 \%)(p=.0017)\end{array}$ \\
\hline
\end{tabular}

of white and chocolate milk over the course of 1 month ( $n=3$ schools). The three conditions in this intervention included treatment 1: increased white milk quantity available in the milk cooler compared to chocolate milk, and treatment 2: chocolate milk is not on display and students must request chocolate milk to receive it (making it the less convenient option), and control group: no changes were made to milk during school lunch. Selection of white milk increased for participants in treatment 1 , but not treatment 2 or the control group (treatment 1: $p<.001$, treatment 2: $p=.125$, control: $p=1.00$, see Table 2) relative to baseline. There was no significant change in milk consumption relative to baseline in treatment 1 , treatment 2 , or the control group (treatment 1 : $p=.50$, treatment $1: p=.89$, control: $p=.69)$.

Hanks and colleagues (2016) [41] implemented a six-week multi-component study that used branded vegetable characters to promote vegetable and salad selection $(n=10$ schools). The four study conditions included treatment 1 : branded vegetables characters featured on vinyl banners in the cafeteria, treatment 2: television promotional segments with branded vegetable characters shown in the cafeteria, and treatment 3: both vinyl banners and television segments, and a control group that did not receive an intervention. Participants in treatment 3 significantly increased their selection of vegetable and salad servings from pre- to postintervention $(p=.028$, see Table 2$)$, while participants in treatments 1 and 2 and the control group did not significantly change their vegetable and salad selection (all $p s=$ not significant, specific $p$-values not reported).
Of the nine multi-component studies [30, 32, 34-37, $41,44,47]$, one (11\%) [35] received a strong quality rating. Ensaff and colleagues' (2015) [35] multi-component intervention ( $n=2$ schools) was implemented over two academic years and included changing food placement, making plant-based food more convenient (through the use of disposable pots/trays used to serve meals, and prefilled pots/trays), and promotional materials (smiley stickers on packaging and posters, end of shelf labels, encouraging posters) to promote healthy food. Study participants were significantly more likely to select items designated as healthy (fruit, vegetables, vegetarian specials, and sandwiches containing salad) during the intervention compared to baseline $(p<.001$, see Table 2$)$. Despite this study's strengths, it is not possible to draw conclusions about the effectiveness of individual intervention components.

\section{Placement/convenience interventions}

Interventions that exclusively fell in the placement/convenience category ( $n=8,40 \%$ of included studies) included changing food, milk, or salad bar placement [29, $36,48]$, changing the timing/order of when foods were served [50, 56], slicing fruit before serving [55], implementing a grab-and-go breakfast cart [45], and introducing water jets [33]. Study designs included three cluster randomized trials $[36,45,55]$, one crossover study [50], one non-randomized controlled trial [33], one repeated cross sectional (longitudinal) study [48], one cross sectional study [29], and one non-controlled trial [56]. 


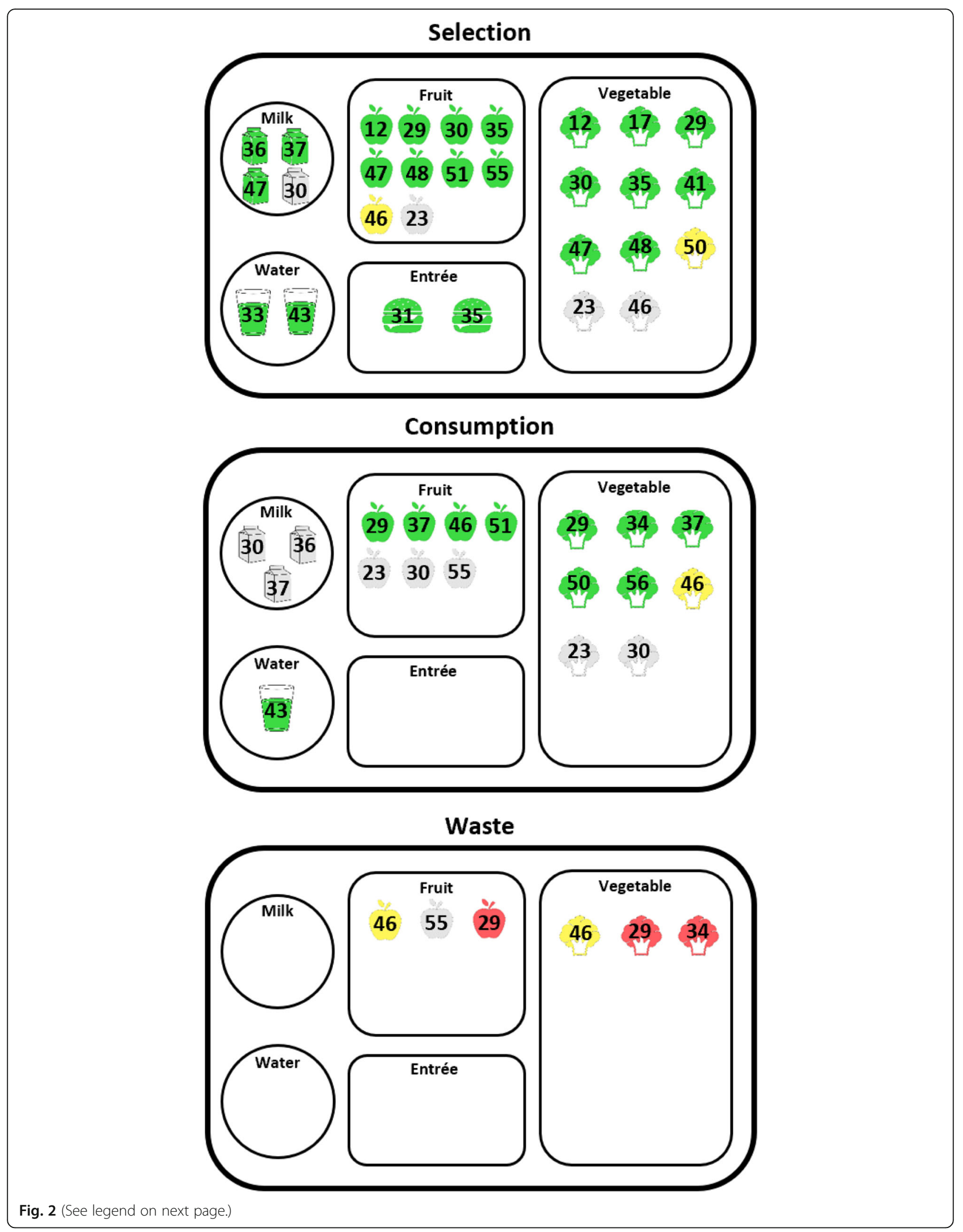


(See figure on previous page.)

Fig. 2 Outcomes from included school meal nudge studies $(n=20)$ listed by school meal component. Note. Positive (green), mixed (yellow), null (grey), and negative (red) outcomes are displayed for each meal component category (vegetables, fruits, entrée, milk, and water). One study [45] (not displayed in this figure) also measured participation in school meals. Only three studies were ranked as high quality [35, 45, 50]. All others were of moderate quality. Outcomes for studies in the following categories 1) placement or convenience, 2) marketing or promotion, 3) variety or portions, and 4) multi-component studies appear in Supplemental Figure 1

Of the eight placement/convenience studies [29, 33, $36,45,48,50,55,56]$, two $(25 \%)$ received strong quality ratings [45, 50]. Larson and colleagues (2018) [45] implemented and evaluated a grab-and-go breakfast cart before school over three academic years ( $n=8$ schools). Participants in the intervention group significantly increased their school breakfast participation relative to baseline ( $p=.003$, see Table 2$)$. An intervention by Redden and colleagues (2015) [50] offered students vegetables in a small cup prior to moving through the lunch line $(n=1$ school). Data was collected over four treatment days and three control days (in which students were not offered extra servings of vegetables) spaced out over a 3 month period. The percent of students who selected carrots did not differ between treatment and control days, and broccoli selection was generally greater on control days $(p<.001$, see Table 2 . Nonetheless, participants increased their consumption of both carrots $(p<.0001)$ and broccoli $(p<.0001)$ on treatment days compared to control days.

Including the studies described above, six placement/ convenience studies had selection outcomes $[29,33,36$, $48,50,55]$, five studies had consumption outcomes [29, $36,50,55,56]$, and two had food waste outcomes [29, 55] (see Supplemental Figure 1). Most studies assessing selection had positive findings $(n=7)$ for vegetables [29, 48], fruits $(29,48,55]$, milk [36], and water [33], while the remaining selection study had a mixed outcome for vegetables [50] Most consumption outcomes were positive $(n=4)$ for vegetables $[29,50,56]$ and fruits [29], while two null consumption outcomes were reported for fruits [55] and milk [36]. Most waste outcomes were negative (i.e. increased waste) for fruits $(n=1)$ [29] and vegetables $(n=1)$ [29], while one null waste outcome was reported for fruits [55]. One (previously described) study found increased school breakfast participation [45]. In examining all outcome categories (participation, selection, consumption, and waste) together, interventions with components related to placement/convenience had twelve positive outcomes, one mixed outcome, three null outcomes, and two negative outcomes.

\section{Marketing/promotion interventions}

Interventions that exclusively fell in the marketing/promotion category ( $n=3,15 \%$ of studies) included one study that used verbal prompts to encourage healthy item selection and/or consumption [51], one study that used nutrition facts labels at point of sale [31], and one previously described study that used branded vegetable characters on promotional materials [41]. These studies used cluster randomized trials $[41,51]$ or nonrandomized controlled trial designs [31]. All three studies received moderate quality ratings.

Studies in this category had three positive selection outcomes for vegetables [41], fruits [51], and entrées [31]. One positive outcome was reported for fruit consumption [51]. No studies measured food waste nor participation. In examining selection, and consumption together, studies with intervention components related to marketing/promotion had four positive outcomes, and no mixed, null, or negative outcomes (see Supplemental Figure 1).

\section{Variety/portions interventions}

Interventions that exclusively fell in the variety/portions category ( $n=2,10 \%$ of studies) included one study that increased portion sizes of fruits and vegetables [46] and one study that implemented salad bars [23]. These studies used crossover [46] and cross-sectional study designs [23]. Selection outcomes included one mixed outcome for fruits [46], and three null outcomes for vegetables $[23,46]$ and fruits [23]. Consumption outcomes included one positive fruit outcome [46], and two null outcomes for vegetables [23] and fruits [23]. Waste outcomes included two mixed outcomes for vegetables [46] and fruits [46]. In examining all three outcome categories together, studies with intervention components related to variety/portions had one positive outcome, four mixed outcomes, five null outcomes, and no negative outcomes (see Supplemental Figure 1).

\section{Discussion}

In this study, we systematically assessed the relationship between behavioral nudges and student selection, consumption, waste, and meal participation in school cafeteria settings. There were only three behavioral nudge studies rated as strong quality, with seventeen studies rated as moderate quality. Results from the moderate and strong quality studies suggest that behavioral nudges generally have a positive relationship with selection, mixed relationship with consumption, negative relationship with waste (i.e. increased waste), and positive relationship with meal participation. However, there were few studies examining the influence of nudge interventions on meal participation or waste. Yet, waste may be 
the most important outcome variable since it takes selection and consumption into account, as well as meal participation, indirectly.

Many ( $n=9,45 \%$ of strong and moderate studies) of the studies included in this review examined nudge interventions with multiple components, most of which evaluated the influence of nudge interventions on selection outcomes. Multi-component and marketing/promotion interventions generally had positive outcomes for selection, and variety/ portions had no studies with overall positive selection outcomes. There are not enough studies evaluating the impact of nudge interventions on consumption behaviors to determine which intervention category is most effective for this outcome, but the current evidence does not suggest that there is an advantage to multi-component studies for consumption. None of the intervention categories exhibit a desirable impact on waste outcomes, but there are few studies published on this outcome.

Given that children generally do not meet the recommended intake for fruits and vegetables, health advocates may be most interested in interventions that increase fruit and vegetable consumption. All studies that found significant vegetable consumption increases $(n=5)$ included at least one placement/convenience intervention, and three of these studies incorporated a strategy to provide a portion of the lunch period to focus on vegetable consumption. Both Redden et al. [50] and Elsbernd et al. [34] served vegetables first in isolation, whereas Zellner et al. [56] offered fruit at the end of the meal instead of during the meal. Taken together, these findings suggest that manipulating the order of when vegetables or their competition (which are often fruits) are served has the most evidence of influencing vegetable consumption relative to other nudge strategies. Health advocates may also be particularly interested in interventions that influence milk consumption, since chocolate milk is the only government subsidized sugar-sweetened beverage included in school meals in the US. Yet, there were no single-component studies of strong or moderate quality that found a positive association between nudge interventions and milk consumption. However, there was one study that found a positive increase in water consumption during school lunch [44]. Kenney and colleagues [44] implemented promotional signs to highlight cafeteria water source locations and water consumption, as well as installed cup dispensers next to cafeteria water fountains. Water consumption increased among the intervention group, but decreased among the control group from pre to post. The authors did not examine if this increase in water consumption occurred at the expense of milk consumption, but other research has demonstrated that mealtime increases in water consumption most often replace chocolate milk consumption and may lead to decreases in body mass index [57].
The results of the three studies that exclusively studied marketing/promotions were encouraging as they consistently yielded positive outcomes. While more studies are needed to confirm the efficacy of these types of nudge interventions overall, there were no studies examining the impact of social norming interventions during school meals. Several recent reviews have highlighted how social norms influence eating behaviors across the lifespan [58-60]. For example, Burger et al. found that participants were significantly more likely to select a healthy snack when they had been informed of others' prior healthy choices [61]. This type of norming intervention would be relatively low cost and easy to implement in the school setting, but more work is needed to ensure these results translate to the school food environment.

There were distinct patterns in the quality criteria scores. Even studies of weak overall quality had moderate to strong data collection methods and measurements, suggesting that valid and reliable measurement techniques are likely required for publication. Most strong and moderate studies did not report any assessment of intervention fidelity. None of the included studies randomly sampled schools or school districts. Schools' focus on academic priorities may increase the likelihood of declining to participate in research studies, making random selection difficult. Also, communities located in close proximity to colleges and universities are likely over sampled due to the need for feasible data collection. Behavioral nudge studies should be considered in the context of the bias created by convenience sampling techniques. In particular, this bias may influence the implementation metrics of behavioral nudges since it is likely that interventions that are acceptable and feasible in a high-resource school may not be so in under-resourced communities. Future studies are needed to consider the efficacy and implementation metrics of behavioral nudges in schools serving high-risk students, as detailed in Fig. 3.

Another key finding of this study was that few papers included relevant environmental and systems factors in the study design. Since there are many factors that influence eating behaviors [62,63], it is necessary to include external factors in the study design, such as maintaining consistency in the available menu items and time available to eat [21] across study groups and observation dates, to best isolate the relationship between the intervention and outcomes of interest. These details also facilitate study replication and systematic review by other researchers. Omissions regarding the availability of salad bars or other student self-service options make the validity of visual observation methods, such as the quarter waste method, of measuring consumption unclear since these methods are not valid when there is variation in the portions of foods selected [64]. Furthermore, interventions should evaluate efficacy in the context of the overall school meal system since interventions that improve 


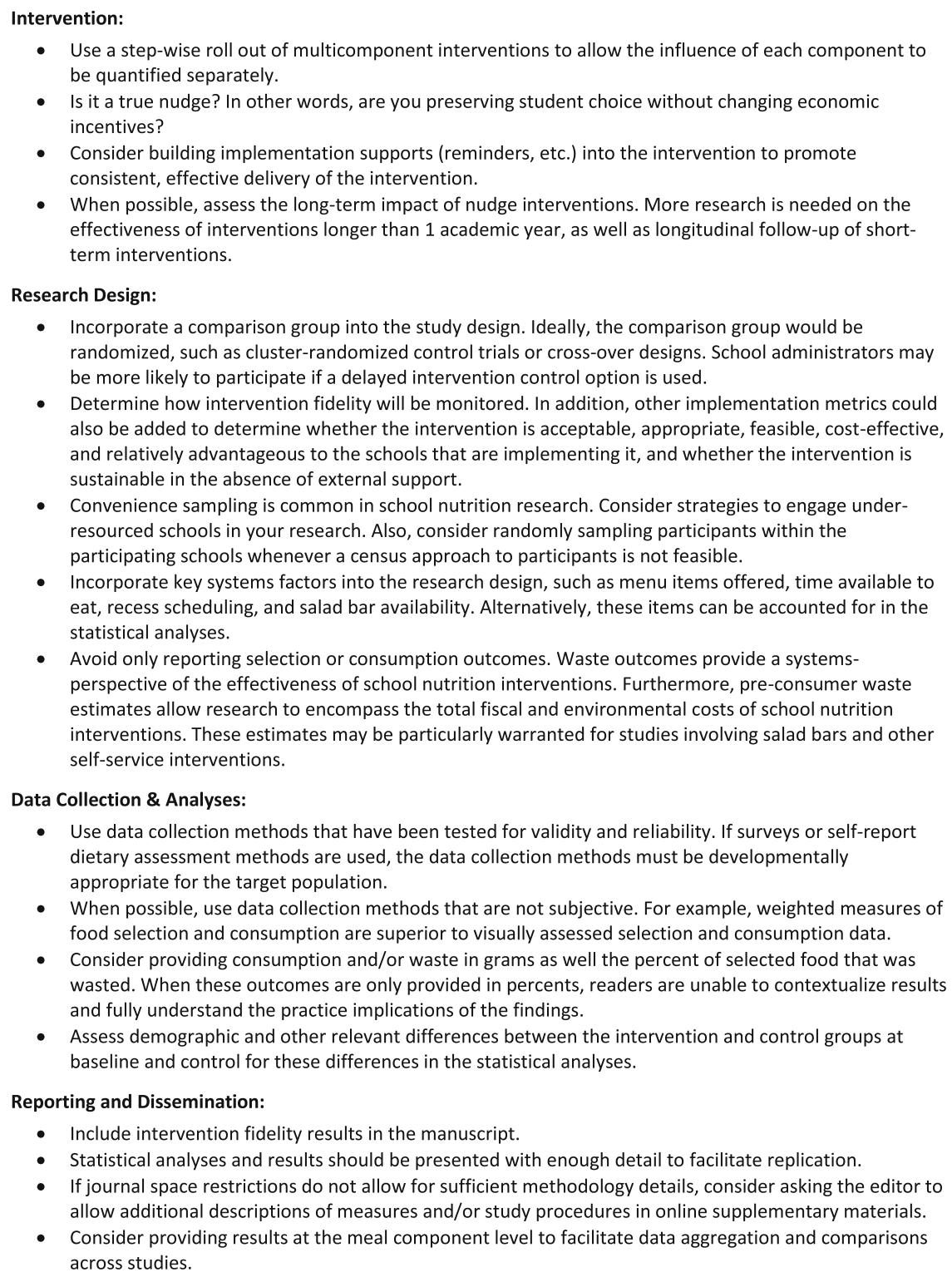

- Use a step-wise roll out of multicomponent interventions to allow the influence of each component to be quantified separately.

- Is it a true nudge? In other words, are you preserving student choice without changing economic incentives?

- Consider building implementation supports (reminders, etc.) into the intervention to promote consistent, effective delivery of the intervention.

- When possible, assess the long-term impact of nudge interventions. More research is needed on the effectiveness of interventions longer than 1 academic year, as well as longitudinal follow-up of shortterm interventions.

Research Design:

- Incorporate a comparison group into the study design. Ideally, the comparison group would be randomized, such as cluster-randomized control trials or cross-over designs. School administrators may be more likely to participate if a delayed intervention control option is used.

- Determine how intervention fidelity will be monitored. In addition, other implementation metrics could also be added to determine whether the intervention is acceptable, appropriate, feasible, cost-effective, and relatively advantageous to the schools that are implementing it, and whether the intervention is sustainable in the absence of external support.

- Convenience sampling is common in school nutrition research. Consider strategies to engage underresourced schools in your research. Also, consider randomly sampling participants within the participating schools whenever a census approach to participants is not feasible.

- Incorporate key systems factors into the research design, such as menu items offered, time available to eat, recess scheduling, and salad bar availability. Alternatively, these items can be accounted for in the statistical analyses.

- Avoid only reporting selection or consumption outcomes. Waste outcomes provide a systemsperspective of the effectiveness of school nutrition interventions. Furthermore, pre-consumer waste estimates allow research to encompass the total fiscal and environmental costs of school nutrition interventions. These estimates may be particularly warranted for studies involving salad bars and other self-service interventions.

Data Collection \& Analyses:

- Use data collection methods that have been tested for validity and reliability. If surveys or self-report dietary assessment methods are used, the data collection methods must be developmentally appropriate for the target population.

- When possible, use data collection methods that are not subjective. For example, weighted measures of food selection and consumption are superior to visually assessed selection and consumption data.

- Consider providing consumption and/or waste in grams as well the percent of selected food that was wasted. When these outcomes are only provided in percents, readers are unable to contextualize results and fully understand the practice implications of the findings.

- Assess demographic and other relevant differences between the intervention and control groups at baseline and control for these differences in the statistical analyses.

Reporting and Dissemination:

- Include intervention fidelity results in the manuscript.

- Statistical analyses and results should be presented with enough detail to facilitate replication.

- If journal space restrictions do not allow for sufficient methodology details, consider asking the editor to allow additional descriptions of measures and/or study procedures in online supplementary materials.

- Consider providing results at the meal component level to facilitate data aggregation and comparisons across studies.

Fig. 3 Methodological considerations and recommendations for designing future behavioral nudge interventions in school cafeterias

selection or consumption but increase pre or post-consumer waste may not be sustainable given schools' limited resources and the increased focus on food waste reduction. For example, salad bars are associated with increased preconsumer waste [65], but none of the studies evaluating salad bar implementation as a method to reduce food waste incorporate pre-consumer waste measurement into the study design. In the interest of intervention sustainability, future salad bar research should incorporate strategies to reduce and measure overall waste instead of only focusing on postconsumer values.

It is also important to note that this review focused on nudge interventions as defined by Thaler and Sunstein; such interventions change the choice environment but do not remove choice or change incentives. Other reviews on the impact of environmental changes on school meal behaviors have included interventions such as removing or banning certain items (e.g., chocolate milk) or changing prices (e.g., reducing prices for healthy options), which do not meet the classical definition of a nudge. Some have argued these tactics, particularly restricting choice, are more effective at changing behavior and are appropriate when we are restricting the choices of children who do not understand the longterm consequences of their choices. Others have pushed back that there is inherent value in preserving choice, 
though, as consumers, even children, find value in having options. Most of the studies $(n=18)$ included in Driessen et al's review of environmental changes to improve weight or food behavior outcomes in school lunch settings were policy interventions, such as removing 'junk' food from school cafeterias and placing caloric restrictions on the food sold during meals [25]. The authors concluded that district, state, or national policies to modify the school food environment have a positive association with improving child food behaviors, such as reductions in BMI, reductions in unhealthy food purchases, and consuming a lower percentage of energy from fat [25]. However, impacts on vegetable consumption were inconsistent [25], suggesting that policy alone may not be enough to improve children's consumption of vegetables. These findings, along with those from our current study, suggest that future research consider placement and/or convenience nudges as a complement to new or existing school nutrition policies.

\section{Limitations}

This systematic review has important limitations to consider. Most notably, the variety of outcomes, reporting, and methodologies did not allow us to conduct a metaanalysis, limiting our ability to quantify the overall impact of nudge interventions. In addition, our conclusions were exclusively limited to peer-reviewed literature which could be subject to publication bias. If so, our findings may overestimate the efficacy of school meal nudge interventions since studies finding null or undesirable results are less likely to be published; however, several null and negative findings were included in our systematic review suggesting that this may be a lesser issue. In addition, school meals may not be the most appropriate setting for nudge interventions since, in many countries, strict school nutrition standards ensure that all foods served are relatively healthy compared to other retail settings where there are much less healthy foods available. However, vegetables are differentially wasted in higher amounts in school meals [66] suggesting that some school meal components may still be appropriate nudge targets.

\section{Conclusions}

Based on the evidence identified in this review, school meal nudges are positively associated with selection behaviors and their influence on consumption is unclear. The limited evidence available suggests that nudges are positively linked to meal participation but have an undesirable, positive association with food waste. Placement/convenience nudge interventions have the most evidence to positively influence vegetable consumption, particularly those that provide vegetable isolation opportunities. Our findings also underscore the need for future research on this topic. As noted in Fig. 3, future work should incorporate implementation metrics, isolate the impact of each intervention, and take systems factors into account.

\section{Additional files}

Additional file 1: Supplemental Figure 1. Category-specific outcomes from included school meal nudge studies $(n=20)$ listed by school meal component.

Additional file 2: Supplementary File. Example article search strategy (PubMed).

\section{Acknowledgements}

The authors would like to acknowledge contributions made to this manuscript by the following undergraduate research assistants: Feifei Chen, Maddie Collanto, Elizabeth Gutierrez, Katherine Hinojosa, Micah Lee, Jenna Lemenager, Fanny Liao, and Joseph Tan.

\section{Authors' contributions}

Study design: BE, RR, and MP; study screening and selection: $B E, N H, R R$, and MP; data extraction: JM, BE, NH, RR, and MP; data analysis: JM; drafting and revision of manuscript: JM, BE, NH, RR and MP. The author (s) read and approved the final manuscript.

\section{Funding}

This research was funded by the USDA National Institute of Food and Agriculture, Hatch project 1015725. The funding agency was not involved with the study design, data analysis, or results interpretation.

\section{Availability of data and materials}

The datasets used and/or analyzed during the current study are available from the corresponding author on reasonable request.

Ethics approval and consent to participate

Not applicable.

\section{Consent for publication}

Not applicable.

\section{Competing interests}

The authors declare that they have no competing interests.

\section{Author details}

${ }^{1}$ Department of Food Science and Human Nutrition, University of Illinois at Urbana-Champaign, 905 South Goodwin Avenue, Urbana, IL 61801, USA.

${ }^{2}$ Department of Agricultural and Consumer Economics, University of Illinois at Urbana-Champaign, 1301 West Gregory Drive, Urbana, IL 61801, USA.

Received: 11 November 2019 Accepted: 9 June 2020

Published online: 19 June 2020

\section{References}

1. Krebs-Smith SM, Guenther PM, Subar AF, Kirkpatrick SI, Dodd KW. Americans do not meet federal dietary recommendations. J Nutr. 2010;140(10):1832-8.

2. U.S. Department of Health and Human Services O of DP and HP. Dietary guidelines advisory committee reports. Nutr Today. 2015;50(4):177-84.

3. Conrad Z, Niles MT, Neher DA, Roy ED, Tichenor NE, Jahns L. Relationship between food waste, diet quality, and environmental sustainability. PLoS One. 2018;13(4):1-18.

4. Gunders D. Wasted: How America is losing up to 40 percent of its food from farm to fork to landfill. NRDC Issue Pap [Internet]. 2012;(August):1-26. Available from: http://www.nrdc.org/food/files/wasted-food-IP.pdf?mkt_tok= 3RkMMJWWfF9wsRonuqjPZKXonjHpfsX56+woXaS1IMI/0ER3fOvrPUfGj/4 ATMphl/qLAzICFpZo2FFUH+GbblFU8g==

5. Thyberg KL, Tonjes DJ. Academic commons drivers of food wastage and their implications for sustainable policy development. Resour Conserv Recycl. 106;110-23. 
6. Gustavsson J, Cederberg C, Sonesson U, van Otterdijk R, Meybeck A. Global food losses and food waste: extent, causes and prevention. Düsseldorf: Food and Agriculture Organization of the United Nations; 2011.

7. US Department of Agriculture Food and Nutrition Services. Nutrition standards in the National School Lunch and school breakfast programs; final rule. Fed Regist [Internet]. 2012;77(17):4088-167 Available from: https:// www.govinfo.gov/content/pkg/FR-2012-01-26/pdf/2012-1010.pdf.

8. Cohen JFW, Richardson S, Parker E, Catalano PJ, Rimm EB. Impact of the new U.S. department of agriculture school meal standards on food selection, consumption, and waste. Am J Prev Med]. 2014;46(4):388-394. Available from: http://dx.doi.org/https://doi.org/10.1016/j.amepre.2013.11. 013.

9. Schwartz MB, Henderson KE, Read M, Danna N, Ickovics JR. New school meal regulations increase fruit consumption and do not increase Total plate waste. Child Obes 2015;11(3):242-247. Available from: http://www. liebertpub.com/doi/https://doi.org/10.1089/chi.2015.0019.

10. Haas J, Cunningham-Sabo L, Auld G. Plate waste attitudes among high school lunch program participants. J Child Nutr Manag. 2014;38(1):n1.

11. Smith SL, Cunningham-Sabo L. Food choice, plate waste and nutrient intake of elementary-and middle-school students participating in the US National School Lunch Program. Public Health Nutr. 2014;17(6):1255-63.

12. Service UD of AER. National School Lunch Program. 2018.

13. Thaler RH, Sunstein C. Nudge: improving decisions about health, wealth, and happiness. New Haven, CT: Yale University Press; 2008.

14. Thorgeirsson, T; Ichiro K. Behavioral economics: merging psychology and economics for lifestyle interventions. Am J Prev Med 2013;44(2):185-189. Available from: http://dx.doi.org/https://doi.org/10.1016/j.amepre.2012.10.008.

15. Liu PJ, Wisdom J, Roberto CA, Liu LJ, Ubel PA. Using behavioral economics to design more effective food policies to address obesity. Appl Econ Perspect Policy. 2014;36(1):6-24.

16. Guthrie JF. Integrating behavioral economics into nutrition education research and practice. J Nutr Educ Behav . 2017:49(8):700-705.e1. Available from: http://dx.doi.org/https://doi.org/10.1016/j.jneb.2016.09.006.

17. Lin Y, Osman M, Ashcroft R. Nudge: concept, effectiveness, and ethics. Basic Appl Soc Psych. 2017;39(6):293-306. Available from: https://doi.org/https:// doi.org/10.1080/01973533.2017.1356304

18. The Smarter Lunchrooms Movement [Internet]. 2017 [cited 2020 Apr 28]. Available from: http://www.ben.cornell.edu/smarter-lunchrooms.html.

19. Robinson E. The science behind Smarter Lunchrooms. Peer J Prepr. 2017;5: e3137v1.

20. Dewey C. Why our schools can't get kids to eat healthy. Wash Post. 2017;24.

21. Cohen J, Jahn J, Richardson S, Cluggish S, Parker E, Rimm E. Amount of time to eat lunch is associated with Children's selection and consumption of school meal entree, fruits, vegetables, and Milk. J Acad Nutr Diet. 2016; 116(1):123-8.

22. Peckham JG, Kropp JD, Mroz TA, Haley-Zitlin V, Granberg EM, Hawthorne N. Socioeconomic and demographic determinants of the nutritional content of National School Lunch Program Entrée Selections. Am J Agric Econ. 2016;99(1):1-17.

23. Adams MA, Pelletier RL, Zive MM, Sallis JF. Salad bars and fruit and vegetable consumption in elementary schools: a plate waste study. J Am Diet Assoc. 2005;105(11):1789-92.

24. Kessler HS. Simple interventions to improve healthy eating behaviors in the school cafeteria. Nutr Rev. 2016;74(3):198-209.

25. Driessen CE, Cameron AJ, Thornton LE, Lai SK, Barnett LM. Effect of changes to the school food environment on eating behaviours and/or body weight in children: a systematic review. Obes Rev. 2014;15(12):968-82.

26. Moher D, Liberati A, Tetzlaff J, Altman DG. Preferred reporting items for systematic reviews and meta-analyses: the PRISMA statement. Ann Intern Med. 2009;151(4):264-9.

27. Smarter Lunchrooms Self-Assessment Scorecard [Internet]. 2016 [cited 2020 Apr 28]. Available from: https:/www.fdacs.gov/content/download/40979/ file/Smarter\%20Lunchrooms\%20Self-Assessment\%202016\%20Scorecard.pdf.

28. Project EPHP. Quality Assessment tool for Quantitative Studies [Internet]. 1998 [cited 2019 Apr 9]. Available from: https://merst.ca/wp-content/ uploads/2018/02/quality-assessment-tool_2010.pdf.

29. Adams MA, Bruening M, Ohri-Vachaspati P, Hurley JC. Location of school lunch salad bars and fruit and vegetable consumption in middle schools: a cross-sectional plate waste study. J Acad Nutr Diet 2016;116(3):407-416. Available from: http://dx.doi.org/https://doi.org/10.1016/j.jand.2015.10.011.

30. Cohen JFW, Richardson SA, Cluggish SA, Parker E, Catalano PJ, Rimm EB. Effects of choice architecture and chef-enhanced meals on the selection and consumption of healthier school foods a randomized clinical trial. JAMA Pediatr. 2015;169(5):431-7.

31. Conklin $M$, Cranage $D$, Lambert C. Nutrition information at point of selection affects food chosen by high school students. J Child Nutr Manag Sch Nutr Assoc. 2005;29(1) Available from: http://docs.schoolnutrition.org/ newsroom/jcnm/05spring/conklin/.

32. Delaney T, Wyse R, Yoong SL, Sutherland R, Wiggers J, Ball K, et al. Cluster randomized controlled trial of a consumer behavior intervention to improve healthy food purchases from online canteens. Am J Clin Nutr. 2017;106(5):1311-20.

33. Elbel B, Mijanovich T, Abrams C, Cantor J, Dunn L, Nonas C, et al. A water availability intervention in New York City public schools: influence on youths' water and milk behaviors. Am J Public Health. 2015;105(2):365-72.

34. Elsbernd SL, Reicks MM, Mann TL, Redden JP, Mykerezi E, Vickers ZM. Serving vegetables first: a strategy to increase vegetable consumption in elementary school cafeterias. Appetite [Internet]. 2016:96:111-5 Available from: https://doi.org/10.1016/j.appet.2015.09.001

35. Ensaff H, Homer M, Sahota P, Braybrook D, Coan S, McLeod H. Food choice architecture: an intervention in a secondary school and its impact on students' plant-based food choices. Nutrients. 2015;7(6):4426-37.

36. Goto K, Waite A, Wolff C, Chan K, Giovanni M. Do environmental interventions impact elementary school students' lunchtime milk selection? Appl Econ Perspect Policy. 2013;35(2):360-76.

37. Greene KN, Gabrielyan G, Just DR, Wansink B. Fruit-promoting smarter lunchrooms interventions: results from a cluster RCT. Am J Prev Med 2017; 52(4):451-458. Available from: http://dx.doi.org/https://doi.org/10.1016/j. amepre.2016.12.015.

38. Hakim S, Meissen G. Increasing consumption of fruits and vegetables in the school cafeteria: the influence of active choice. J Health Care Poor Underserved. 2013;24(2):145-57.

39. Hanks AS, Just DR, Smith LE, Wansink B. Healthy convenience: nudging students toward healthier choices in the lunchroom. J Public Heal (United Kingdom). 2012;34(3):370-6.

40. Hanks AS, Just DR, Wansink B. Smarter lunchrooms can address new school lunchroom guidelines and childhood obesity. J Pediatr 2013;162(4):867-869. Available from: http://dx.doi.org/https://doi.org/10.1016/j.jpeds.2012.12.031.

41. Hanks AS, Just DR, Brumberg A. Marketing vegetables in elementary school cafeterias to increase uptake. Pediatrics. 2016;138(2):e20151720.

42. Hunsberger M, McGinnis P, Smith J, Beamer BA, O'Malley J. Calorie labeling in a rural middle school influences food selection: findings from community-based participatory research. J Obes. 2015:2014:1-7.

43. Johnson CC, Myers L, Mundor AR, O'Malle K, Spruance LA, Harris DM. Lunch salad bars in New Orleans' middle and high schools: Student intake of fruit and vegetables. Int J Environ Res Public Health. 2017;14(4).

44. Kenney EL, Gortmaker SL, Carter JE, Howe MCW, Reiner JF, Cradock AL. Grab a cup, fill it up! An intervention to promote the 1 of drinking water and increase student water consumption during school lunch. Am J Public Health. 2015;105(9):1777-83.

45. Larson N, Wang Q, Grannon K, Wei S, Nanney MS, Caspi C. A low-cost, graband-go breakfast intervention for rural high school students: changes in school breakfast program participation among at-risk students in Minnesota. J Nutr Educ Behav. 2018;50(2):125-132.e1. Available from: https://doi.org/ https://doi.org/10.1016/j.jneb.2017.08.001.

46. Miller N, Reicks M, Redden JP, Mann T, Mykerezi E, Vickers Z. Increasing portion sizes of fruits and vegetables in an elementary school lunch program can increase fruit and vegetable consumption. Appetite 2015:91: 426-430. Available from: http://dx.doi.org/https://doi.org/10.1016/j.appet. 2015.04.081.

47. Miller GF, Gupta S, Kropp JD, Grogan KA, Mathews A. The effects of preordering and behavioral nudges on National School Lunch Program participants' food item selection. J Econ Psychol 2016;55:4-16. Available from: http://dx.doi.org/https://doi.org/10.1016/j.joep.2016.02.010.

48. Moreno-Black G, Stockard J. Salad bar selection patterns of elementary school children. Appetite. 2017;120:136-144. Available from: https://doi.org/ https://doi.org/10.1016/j.appet.2017.08.034.

49. Morizet D, Depezay L, Combris P, Picard D, Giboreau A. Effect of labeling on new vegetable dish acceptance in preadolescent children. Appetite 2012; 59(2):399-402. Available from: http://dx.doi.org/https://doi.org/10.1016/j. appet.2012.05.030

50. Redden JP, Mann T, Vickers Z, Mykerezi E, Reicks M, Elsbernd S. Serving first in isolation increases vegetable intake among elementary schoolchildren. PLoS One. 2015;10(4):1-14 
51. Schwartz MB. The influence of a verbal prompt on school lunch fruit consumption: a pilot study. Int J Behav Nutr Phys Act. 2007;6(291):51-5.

52. Siegel RM, Anneken A, Duffy C, Simmons K, Hudgens M, Kate Lockhart M, et al. Emoticon use increases plain milk and vegetable purchase in a school cafeteria without adversely affecting Total Milk purchase. Clin Ther. 2015; 37(9):1938-43. Available from: https://doi.org/10.1016/j.clinthera.2015.07.016.

53. Swanson M, Branscum A, Nakayima PJ. Promoting consumption of fruit in elementary school cafeterias. The effects of slicing apples and oranges. Appetite. 2009;53(2):264-7.

54. Thompson E, Johnson DC, Leite-Bennett A, Ding Y, Mehrotra K. The impact of multiple strategies to encourage fruit and vegetable consumption during school lunch. J Sch Health. 2017;87(8):616-22.

55. Wansink B, Just DR, Hanks AS, Smith LE. Pre-sliced fruit in school cafeterias: Children's selection and intake. Am J Prev Med 2013;44(5):477-480. Available from: http://dx.doi.org/https://doi.org/10.1016/j.amepre.2013.02.003.

56. Zellner DA, Cobuzzi JL. Just dessert: serving fruit as a separate "dessert" course increases vegetable consumption in a school lunch. Food Qual Prefer 2016;48:195-198. Available from: http://dx.doi.org/https://doi.org/10. 1016/j.foodqual.2015.09.013.

57. Schwartz A, Leardo M, Aneja S, Elbel B. Effect of a school-based water intervention on child body mass index and obesity. JAMA Pediatr. 2016; 170(3):220-6.

58. Higgs S. Social norms and their influence on eating behaviours. Appetite. 2015;86:38-44

59. Cruwys T, Bevelander K, Hermans R. Social modeling of eating: a review of when and why social influence affects food intake and choice. Appetite. 2015;86:3-18.

60. Salvy S, de la Haye K, Bowker J, Hermans R. Influence of peers and friends on children's and adolescents' eating and activity behaviors. Physiol Behav. 2012;106(3):369-78.

61. Burger JM, Bell H, Harvey K, Johnson J, Stewart C, Dorian K, et al. Nutritious or delicious? The effect of descriptive norm information on food choice. J Soc Clin Psychol. 2010;29(2):228-42.

62. Story M, Neumark-Sztainer D, French S. Individual and environmental influences on adolescent eating behaviors. J Am Diet Assoc. 2002;102(3):40-51.

63. Harrison K, Bost K, McBride B, Donovan S, Grigsby-Toussaint D, Kim J, et al. Toward a developmental conceptualization of contributors to overweight and obesity in childhood: the six-Cs model. Child Dev Perspect. 2011;5(1):50-8.

64. Bean M, Raynor H, Thornton L, Sova A, Stewart M, Mazzeo S. Reliability and validity of digital imagery methodology for measuring starting portions and plate waste from school salad bars. J Acad Nutr Diet. 2018;118(8):1482-9.

65. Prescott M, Herritt C, Bunning M, Cunningham-Sabo L. Resources, barriers, and tradeoffs: a mixed methods analysis of school pre-consumer food waste. J Acad Nutr Diet. 2019:119(8):1270-83.

66. Shanks C, Banna J, Serran E. Food waste in the National School Lunch Program 1978-2015: a systematic review. J Acad Nutr Diet. 2017;117(11): 1792-807.

\section{Publisher's Note}

Springer Nature remains neutral with regard to jurisdictional claims in published maps and institutional affiliations.

Ready to submit your research? Choose BMC and benefit from:

- fast, convenient online submission

- thorough peer review by experienced researchers in your field

- rapid publication on acceptance

- support for research data, including large and complex data types

- gold Open Access which fosters wider collaboration and increased citations

- maximum visibility for your research: over $100 \mathrm{M}$ website views per year

At $\mathrm{BMC}$, research is always in progress.

Learn more biomedcentral.com/submissions 